Journal of Computer Science 5 (4): 250-254, 2009

ISSN 1549-3636

(C) 2009 Science Publications

\title{
Color Image Reconstruction Using A New R'G'I Model
}

\author{
${ }^{1}$ Akram A. Moustafa and ${ }^{2}$ Ziad A. Alqadi \\ ${ }^{1}$ Department of Computer Science, \\ Al al-Bayt University, P.O. Box 922283, 11192, Mafraq, Jordan \\ ${ }^{2}$ Faculty of Engineering, Al-Balqa Applied University, Amman, Jordan
}

\begin{abstract}
Problem statement: A new color model for digital image was discussed; this model can be used to separate low and high frequencies in the image without loosing any information from the image. Approach: A comparative study between different color models (RGB, HSI) applied to a very large microscopic image analysis and the proposed model was presented. Such analysis of different color models is needed in order to carry out a successful detection and therefore a classification of different Regions of Interest (ROIs) within the image. Results: This, in turn, allows both distinguishing possible ROIs and retrieving their proper color for further ROI analysis. This analysis was not commonly done in many biomedical applications that deal with color images. Other important aspects were the computational cost of the different processing algorithms according to the color model. The proposed model took these aspects into consideration and the experimental results showed the advantages of proposed model compared with HSI model by decreasing the computational time for various image-processing operations. Conclusion: The proposed model can be used in different application such as separating low and high frequencies from the image.
\end{abstract}

Key words: Digital Image Processing (DIP), RGB, HSI, Direct transform, inverse transform, color model

\section{INTRODUCTION}

Color models: Digital image, or bitmap, is a structure representing a rectangular grid of pixels, or points of colors, on a computer monitor. The color of each pixel defined in the RGB color space where each pixel defined by three bytes-one byte each for red, green and blue.

Digital image processing methods include various operations such as:

- Tone processing: Brightening, lightening, contrast stretching (Fig. 1)

- Image enhancement in spatial domain (histogram processing, gamma correction, image filtration in spatial domain and other methods)

Color models provide a standard way to specify a particular color, by defining a 3D coordinate system and a subspace that contains all constructible colors within a particular model. Any color that can be specified using a model will correspond to a single point within the subspace it defines. Each color model is oriented towards either specific hardware (RGB, CMY, YIQ), or image processing applications (HSI) ${ }^{[1-3]}$.
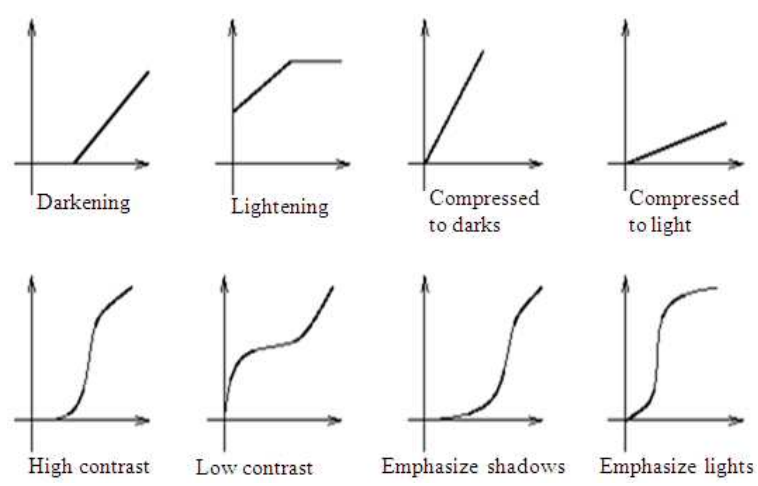

Fig. 1: Tone processing

The RGB model: In the RGB model, an image consists of three independent image planes, one in each of the primary colors: red, green and blue. Specifying particular colors is by specifying the amount of each of the primary components present. Figure 1 shows the geometry of the RGB color model for specifying colors using a Cartesian coordinate system. The grayscale spectrum, i.e., those colors made from equal amounts of each primary, lies on the line joining the black and white vertices ${ }^{[4-6]}$.

Corresponding Author: Akram A. Moustafa, Department of Computer Science, Al al-Bayt University, P.O. Box 922283, 11192, Mafraq, Jordan 


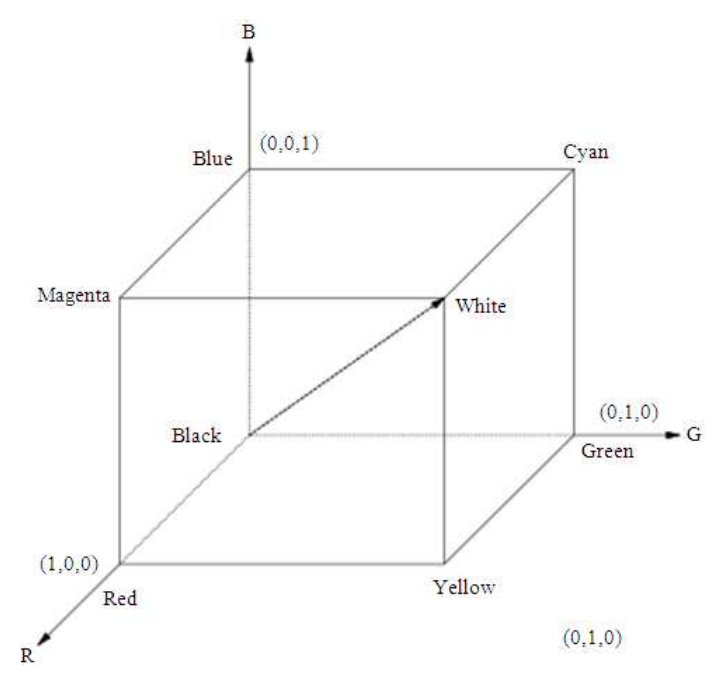

Fig. 2: The RGB color cube.
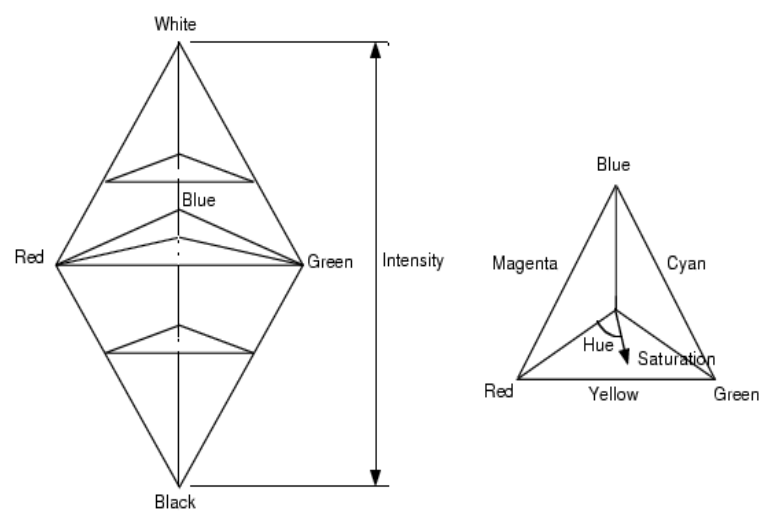

Fig. 3: The HSI model

The grayscale spectrum lies on the line joining the black and white vertices.

This is an adaptive model, i.e., the colors present in the light add to form new colors and is appropriate for the mixing of colored light for example.

The RGB model is used for color monitors and most video cameras.

The HSI model: As mentioned above, color may be specified by the three quantities hue, saturation and intensity. This is the HSI model and the entire space of colors that may be specified in this way is shown in Fig. 3.

The HSI model showing the HSI solid on the left and the HSI triangle on the right, formed by taking a horizontal slice through the HSI solid at a particular intensity. Hue is measured from red and saturation is given by distance from the axis. Colors on the surface of the solid are fully saturated, i.e., pure colors and the grayscale spectrum is on the axis of the solid. For these colors, hue is undefined.

Conversion between the RGB model and the HSI model is quite complicated. The intensity is given by where the quantities R, G and B are the amounts of the red, green and blue components, normalized to the range $[0,1]$. The intensity is therefore just the average of the red, green and blue components. The saturation is given by ${ }^{[5-9]}$ :

$$
\mathrm{H}=\cos ^{-1}\left\{\frac{0.5[((\mathrm{R}-\mathrm{G})+(\mathrm{R}-\mathrm{B}))]}{\sqrt{(\mathrm{R}-\mathrm{G})^{2}+(\mathrm{R}-\mathrm{B})(\mathrm{G}-\mathrm{B})}}\right\}
$$

$\mathrm{S}=1-\frac{3}{(\mathrm{R}+\mathrm{G}+\mathrm{B})}[\min (\mathrm{R}, \mathrm{G}, \mathrm{B})]$

$\mathrm{I}=\frac{1}{3}(\mathrm{R}+\mathrm{G}+\mathrm{B})$

for the GB sector $\left(120^{\circ} \leq \mathrm{H} \leq 240^{\circ}\right)$ :

$$
\begin{aligned}
& B=I(1-S) \\
& H=H-120^{\circ} \\
& R=I\left[1+\frac{S \cos (H)}{\cos \left(60^{\circ}-H\right)}\right] \\
& R=I(1-S) \\
& G=3 \cdot I-(R+B) \\
& G=I\left[1+\frac{S \cos (H)}{\cos \left(60^{\circ}-H\right)}\right]
\end{aligned}
$$

for the BR sector $\left(240^{\circ} \leq \mathrm{H} \leq 360^{\circ}\right)$ :

$$
\begin{aligned}
& B=3 \cdot I-(R+G) \\
& H=H-240^{\circ} \\
& G=I \cdot(1-S) \\
& B=I\left[1+\frac{S \cos (H)}{\cos \left(60^{\circ}-H\right)}\right] \\
& R=3 \cdot I-(G+B)
\end{aligned}
$$

Where the $\min (\mathrm{R}, \mathrm{G}, \mathrm{B})$ term is really just indicating the amount of white present. If any of R, G or B is zero, there is no white and we have a pure color ${ }^{[1]}$. 


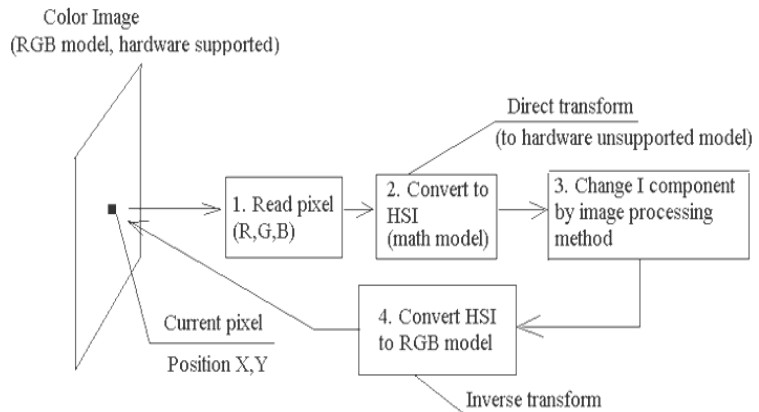

Fig. 4: Standard color image processing algorithm

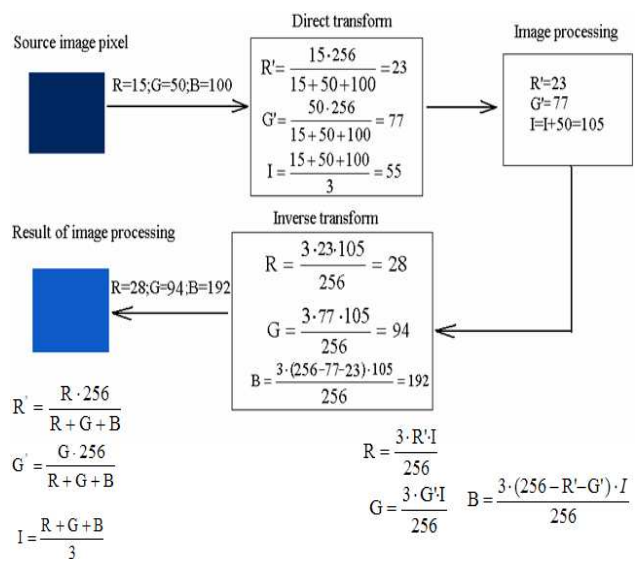

Fig. 5: Example of digital image processing using proposed color model

All methods of DIP described above can be applied directly only in gray scale images (color range $[0 \ldots$ 255]).

For color images, standard image processing methods possible to provide according to the algorithm (Fig. 4).

The proposed color model for digital image processing: The proposed color model includes the following Stages of digital image processing:

- Direct transforms (RGB to R' G'I conversion)

$$
\begin{aligned}
& R=\frac{R \cdot 256}{(R+G+B)} \\
& G=\frac{G \cdot 256}{(R+G+B)} \\
& I=\frac{R+G+B}{3}
\end{aligned}
$$

Image processing using only the intensity I.
Apply the method proposed in ${ }^{[10]}$ to separate low and high frequencies in the black and white image. Inverse transforms:

$$
\begin{aligned}
\mathrm{R} & =\frac{3 \cdot \mathrm{R}^{\prime} \cdot \mathrm{I}}{(256)} \\
\mathrm{G} & =\frac{3 \cdot \mathrm{G}^{\prime} \cdot \mathrm{I}}{(256)} \\
\mathrm{B} & =\frac{3 \cdot\left(256-\mathrm{R}^{\prime}-\mathrm{G}^{\prime}\right) \cdot \mathrm{I}}{(256)}
\end{aligned}
$$

Figure 5 shows an example of how to use this model.

The proposed model needs (also as other models):

Evaluation the transform on its gamut: Example: Brightening +100 (gray scale source image)

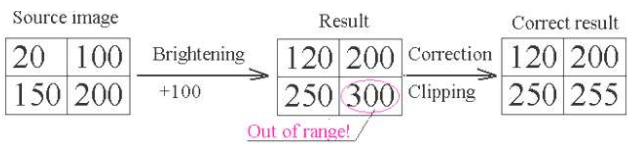

Same problem can appear in our model. Example:

- Source image: $R=15, G=50, B=100$

- Direct transform (to RGI): R' = 23, G' $=77, \mathrm{I}=55$

- Image processing: $\mathrm{R}^{\prime}=23, \mathrm{G}^{\prime}=77, \mathrm{I}=\mathrm{I}+100=155$

- Inverse transform: $\mathrm{R}=41 ; \mathrm{G}=139 ; \mathrm{B}=283>255$ out of gamut Result: Blue color $=284$ $($ Decimal $)=100011100($ Binary $)=$ clipped to $11100=28($ Decimal $)$

\section{Inverse transforms correction:}

$\mathrm{R}=\frac{3 \cdot \mathrm{R}^{\prime} \cdot \mathrm{I}}{(256)}=255(\max )$

$\mathrm{G}=\frac{3 \cdot \mathrm{G}^{\prime} \cdot \mathrm{I}}{(256)}=255(\max )$

$\mathrm{I}=\frac{3 \cdot\left(256-\mathrm{R}^{\prime}-\mathrm{G}^{\prime}\right) \cdot \mathrm{I}}{(256)}=255(\max )$

Equations for gamut correction:

$$
\begin{aligned}
& \text { if }\left(I>\frac{21760}{R^{\prime}}\right) \text { then }=\frac{21760}{R^{\prime}} ; \\
& \text { if }\left(I>\frac{21760}{G^{\prime}}\right) \text { then }=\frac{21760}{G^{\prime}} \\
& \text { if } \left.(I\rangle \frac{21760}{256-R^{\prime}-G^{\prime}}\right) \text { thenI }=\frac{21760}{256-R^{\prime}-G^{\prime}}
\end{aligned}
$$


- Source image: $\mathrm{R}=15, \mathrm{G}=50, \mathrm{~B}=100$

- Direct transform (to RGI): $\mathrm{R}^{\prime}=23, \mathrm{G}^{\prime}=77, \mathrm{I}=55$

- Image processing: $\mathrm{R}^{\prime}=23, \mathrm{G}^{\prime}=77, \mathrm{I}=\mathrm{I}+100=155$

- for R: $\mathrm{I}=155<944, \mathrm{OK}$

for G: $I=155<283$, OK

for $\mathrm{B}$ : $\mathrm{I}=155<139$ : Out of gamut; Use $\mathrm{I}=139$ (result of correction)

- Inverse transform: $\mathrm{R}=38 ; \mathrm{G}=125 ; \mathrm{B}=255$ (all colors in the range of it's gamut)

Now this model can be applied to the proposed method in ${ }^{[10]}$ and can be implemented in following way:

- Read the color image

- Perform direct transoms

- Separate low and high frequencies in the black and white image using the method proposed in ${ }^{[10]}$

- Return back the black and white frequencies to color frequencies using inverse transforms

\section{MATERIALS AND METHODS} lab.

The proposed model was implemented using mat

More than 500 color images were treated using HSI model.

For each color model we find the total time needed to perform each of the following tasks:

- Direct conversion (transform)

- Inverse conversion

- Inverse conversion with gamut correction

- Brightness with gamut correction

- Contrast stretching with gamut correction

- Histogram equalization with gamut correction

- Histogram equalization without gamut correction

The same tasks for each color image were treated using the proposed R'G'I model and for each task the acceleration was calculated.

\section{RESULTS}

The proposed model was implemented using deferent color images with deferent type of image processing operations (Brightening, contrast stretching and image equalization).

The implementation results were compared with other results obtained by using other existing models.

Table 1 contains the experimental results and shows the enhancements, which can be achieved using the proposed model.
Table 1: Measured time of conversion

\begin{tabular}{|c|c|c|c|}
\hline Test & $\begin{array}{l}\text { R'G'I model } \\
(\mathrm{ms}) \text { (proposed } \\
\text { model) }\end{array}$ & $\begin{array}{l}\text { HSI } \\
\text { model } \\
(\mathrm{ms})\end{array}$ & Acceleration \\
\hline Direct transforms & 280 & 1024 & 3.65 \\
\hline Inverse Transforms (IT) & 205 & 939 & 4.50 \\
\hline IT with gamut correction & 315 & 939 & 1.84 \\
\hline $\begin{array}{l}\text { Brightening with } \\
\text { gamut correction }\end{array}$ & 1546 & 2170 & 1.40 \\
\hline $\begin{array}{l}\text { Contrast stretching } \\
\text { (with gamut correction) }\end{array}$ & 1680 & 2265 & 1.35 \\
\hline $\begin{array}{l}\text { Histogram equalization } \\
\text { (HE) with gamut correction }\end{array}$ & 1985 & 2568 & 1.29 \\
\hline HE without gamut correction & 1116 & 2568 & 2.30 \\
\hline
\end{tabular}

Acceleration $=($ Time using HSI model/time using proposed model $)^{*} 100 \%$

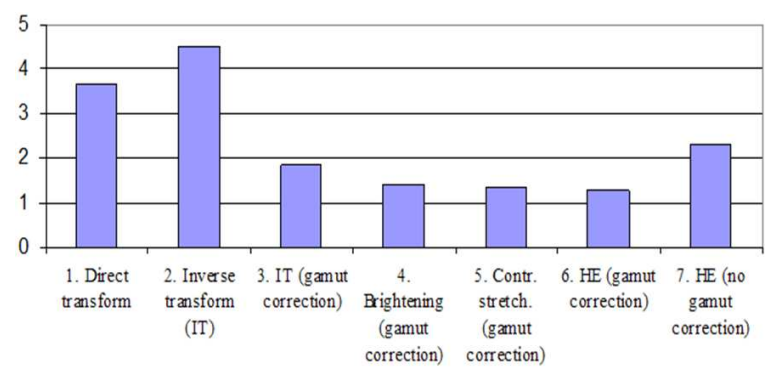

Fig. 6: Speed up using proposed color model model.

Figure 6 shows the speedup using the proposed

\section{DISCUSSION}

Direct and inverse conversions using the proposed model were tested using different images. The proposed conversion was tested using an original color image to get the gray image and without applying any processing we got the color image using inverse conversion, the experimental results showed that the correlation between the original image and the obtained color image was always equal one, which means full matching between the original image and the obtained one.

The HSI and R'G'I models were applied and the experimental results show that the proposed model has always a speed-up greater than 1 in different steps of processing such as: Direct conversion, inverse conversion and image stretching and image equalization.

The proposed model was implanted using a lot of color images and the obtained results shows that this medal can replace the HSI model because of its efficiency.

\section{CONCLUSION}

A new color model for digital image processing was proposed, the experimental results show the 
efficiency of using this model comparing with other existing models performing deferent types of image processing operations.

The acceleration factor was computed for the proposed method and HSI method, the obtained results show that the acceleration (speedup) ranges from 1.29 (when performing image equalization) to 4.5 (when performing inverse transforms).

\section{REFERENCES}

1. Burkhardt, H. and B. Neumann, 1998. ECCV '98. Lecture Notes Comput. Sci., 1406: 610-622.

2. Rojo, M.G., G.B. García, C.P. Mateos, J.G. García and M.C. Vicente, 2006. Critical comparison of 31 commercially available digital slide systems in pathology. Int. J. Surg. Pathol., 14: 285-305. http://www.ncbi.nlm.nih.gov/pubmed/17041192

3. Kimmel, R., 1999. Demosaicing: Image reconstruction from color $\mathrm{CCD}$ samples image processing. IEEE Trans., 8: 1221-1228. DOI: 10.1109/83.784434

4. Foley, J.D., A. van Dam, S.K. Feiner and J.F. Hughes, 1990. Computer Graphics, Principles and Practice. 2nd Edn., Addison-Wesley, Reading, ISBN: 0-20112110-7, pp: 1174.

5. Kang, H.R., 1993. Resolution conversion of bitmap, images. US Patent 5270836. http://www.patentstorm.us/patents/5270836.html

6. Waheeb, A., A. Moustafa and Z. Alqadi, 2009. Gray image reconstruction. Eur. J. Sci. Res., 27: $167-173$.

http://www.eurojournals.com/ejsr_27_2_01.pdf
7. Gao, M., P. Bridgman and S. Kumar, 2003. Computer aided prostate cancer diagnosis using image enhancement and JPEG2000. Proceeding of the SPIE International Conference on Applications of Digital Image Processing, Aug. 5-8, San Diego CA., pp: 323-334. http://cat.inist.fr/?aModele $=$ afficheN\&cpsidt $=1588$ 3017

8. Li, Y., D. Lu, X. Lu and J. Liu, 2004. Interactive color image segmentation by region growing combines with image enhancement based on Bezier model. Proceedings of the 3rd International Conference on Image and Graphics, Dec. 18-20, IEEE Xplore Press, USA., pp: 96-99. DOI: 10.1109/ICIG.2004.89

9. Begelrnan, G., E. Gur, E. Rivlin, M. Rudzsky and Z. Zalevsky, 2004. Cell nuclei segmentation using fuzzy logic engine. Proceeding of the IEEE Intern Conference on Image Processing, Oct. 24-27, IEEE Xplore Press, USA., pp: 2937-2940. DOI: 10.1109/ICIG.2004.89

10. Hu, M.P. and X.Y. Ding, 2004. Automated cell nucleus segmentation using improved snake. Proceeding of the Intern Conference on Image Processing, Oct. 24-27, IEEE Xplore Press, USA., pp: 2737-2740. DOI: 10.1109/ICIP.2004.1421670

11. Wyszecki, G. and W.S. Stiles, 2000. Color Science: Concepts and Methods. Quantitive Data and Formulae. 2nd Edn., Wiley, ISBN: 10: 0471399183, pp: 968. 